\title{
Design of Single Band Slotted Microstrip Patch Antenna for WiMax Band
}

\author{
Hardeep Kaur \\ Student \\ Department of Electronics and Communication \\ Lovely Professional University, Phagwara (Punjab)
}

\author{
Neha Ahuja \\ Assistant Professor \\ Department of Electronics and Communication \\ Lovely Professional University, Phagwara (Punjab)
}

\begin{abstract}
This paper, presents a single band Microstrip Patch Antenna for WiMax application. The planner geometry of designed antenna consists of ground, substrate, patch, feed and slot. The designed antenna has been optimized using CST Microwave studio software for 3.41-3.64 GHz band with corresponding bandwidth of $223 \mathrm{MHz}$. The gain of $3.8 \mathrm{dBi}$ and directivity of $4.51 \mathrm{~dB}$ has been achieved with corresponding impedance of $50.02 \mathrm{ohm}$. The corresponding simulated results of this designed antenna have been illustrated in this paper.
\end{abstract}

\section{General Terms}

Microstrip Patch Antenna, Simulation, Antenna Geometry.

\section{Keywords}

CST Software, Rectangular Slotted Microstrip Patch Antenna, Microstrip feed line, Single frequency, Reduced Ground plane.

\section{INTRODUCTION}

Microstrip antennas is a simplest form of antenna configuration. It consists of a radiating patch on one side of dielectric substrate $(\mathrm{Cr} \leq 10)$ and it has a ground plane on other side. A microstrip patch antenna consists of a many conducting patch of any planar or nonplanar geometry. The rectangular and circular patches are the basic and mostly common used for microstrip antennas because of ease of fabrication system. The microstrip antenna have various advantages such as small size, low-cost of fabrication process, low profile of antenna, light in weight, ease of installation process and integration with many feed types. The applications of these type of antennas in various fields such as in the medical applications, satellite and of course even in the military systems just like in the rockets, aircrafts missiles [1]. However, the microstrip antenna has a low gain and a narrow bandwidth. To overcome its limitation of narrow impedance bandwidth and low gain, many techniques have been proposed. In this proposed antenna single slot and reduced ground techniques has been used. However, by using single slot patch with the walls at the substrate, one can obtain enhanced impedance band width. A simple patch antenna with basic rectangular patch operates in a single frequency band. A patch antenna planned to operate at a centre resonance frequency mounted on a substrate having dielectric constant $\varepsilon_{\mathrm{r}}$ would have length $\mathrm{L}$ and width $\mathrm{W}$ of the patch as calculaed from equations [2]. The radiation characteristics of antennas (current distribution, pattern, impedance) mounted on finite size ground planes can be some modification considerably, especially in regions of very low intensity, by the effects of the edges [3]. In microstrip patch antenna there are some wellknown methods to increase the bandwidth of patch antennas, such as, cutting a resonant slot in the patch, reduced ground plane, the use of thick substrate, the use of a low dielectric substrate, the use of a low dielectric substrate, the use of various impedance matching feeding techniques, the use of slot antenna geometry and multi-resonator stack configurations. However, the bandwidth and the size of an antenna are generally reciprocal conflicting properties that are improvement of one of the characteristics normally results in degradation of the other one [4]. Various shapes of cutting slots and slits have been designed on patch antennas to reduce their size. These shapes of slots that are embedded on the antenna are used to increase the surface current path. To decrease the resonant frequency of an antenna for a given surface area, the current path must be maximized within the area [5]. For efficient radiation, the size of Microstrip antenna should be $\lambda / 2$. If the size reduces less than $\lambda / 2$, the radiation efficiency of antenna decreases along with other antenna parameters. The miniaturization of antenna and improvement in bandwidth can be achieved by etching the slot in ground and patch of Microstrip antenna of proper length and width value [6].

\section{DESIGN ANTENNA GEOMETRY}

The proposed antenna used for WiMax application. In the WiMax application the used antenna size does not bulky in size [7]. A proposed Microstrip patch antenna starting with a rectangular patch, substrate and ground plane. These rectangular parameters are simulated to optimize the performance and ending with slotted patch and reduced ground plane. The proposed antenna use Microstrip Line feed impedance is $50 \mathrm{ohm}$. The proposed antenna has dimensions given below:

$\begin{array}{ll}\text { Substrate Thickness }(h)= & 1.524 \\ \text { Relative Permittivity }\left(\varepsilon_{\mathrm{r}}\right)= & 4.4 \\ \text { Length of Patch }(\mathrm{L})= & 8.90 \mathrm{~mm} \\ \text { Width of Patch }(\mathrm{W})= & 13 \mathrm{~mm} \\ \text { Length of Ground }(\mathrm{L})= & 14 \mathrm{~mm} \\ \text { Width of Ground }(\mathrm{W})= & 9.5 \mathrm{~mm}\end{array}$

For designing the proposed rectangular microstrip patch antenna the equations are used to calculate the dimensions of antenna. The designed antenna is resonating at $3.52 \mathrm{GHz}$ and simulated results using CST software.

$$
L_{e f f}=\frac{C}{2 f_{o} \sqrt{\varepsilon_{\text {reff }}}}
$$




$$
\begin{gathered}
\boldsymbol{W}=\frac{\lambda_{\circ}}{2}\left[\frac{\xi_{r}+\mathbf{1}}{2}\right]^{-\frac{1}{2}} \\
\varepsilon_{\text {reff }}=\frac{\varepsilon_{r}+1}{2}+\frac{\varepsilon_{r}-1}{2}\left[1+12 \frac{h}{W}\right]_{(3)}^{-\frac{1}{2}} \\
\frac{\Delta L}{h}=0.412 \frac{\left(\varepsilon_{\text {reff }}+0.3\right)\left(\frac{W}{h}+0.264\right)}{\left(\varepsilon_{\text {reff }}-0.258\right)\left(\frac{W}{h}+0.8\right)}
\end{gathered}
$$

$$
\begin{aligned}
& L=L_{\text {eff }}-2 \Delta L \\
& L_{g}=6 h+L
\end{aligned}
$$

$$
W_{s}=6 h+W
$$

The terms used in these equations are described below:

$$
\begin{aligned}
& \mathrm{L}_{\text {eff }}=\text { effective length } \\
& \mathrm{c}=\text { speed of light } \\
& \mathrm{f}_{\mathrm{o}}=\text { resonant frequency } \\
& \varepsilon_{\text {reff }}=\text { effective permittivity } \\
& \mathrm{W}=\text { width of patch } \\
& \mathrm{h}=\text { substrate thickness } \\
& \varepsilon_{\mathrm{r}}=\text { relative permittivity } \\
& \mathrm{L}_{\mathrm{g}}=\text { length of Ground } \\
& \mathrm{W}_{\mathrm{g}}=\text { width of Ground }
\end{aligned}
$$

\section{DESIGN PARAMETER}

The CST view of the designed antenna is shown in Figure1. CST Microwave Studio software view of designed microstrip line fed patch antenna with slot for single band operation for WiMax.

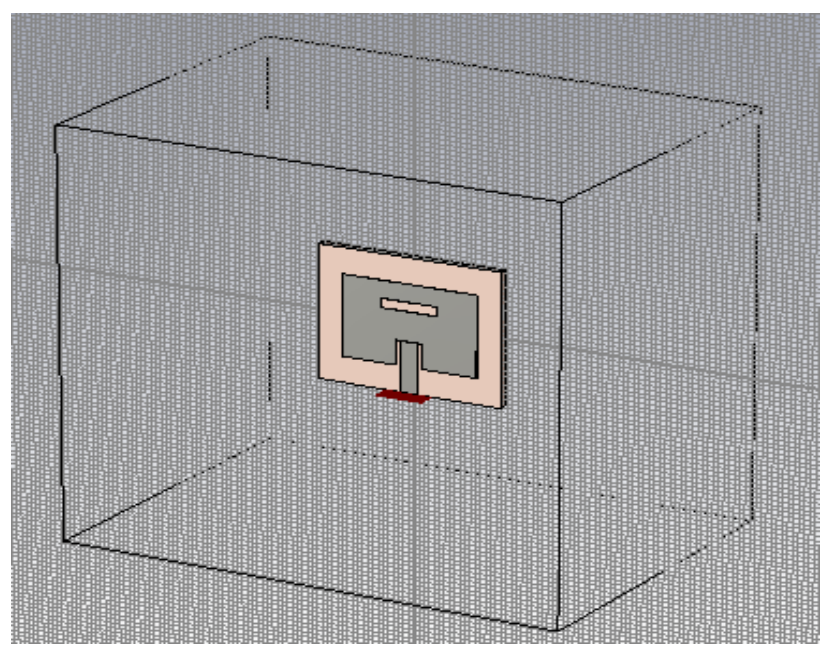

Figure 1: CST view of proposed antenna
The back view of the designed microstrip patch antenna is shown in Figure 2.

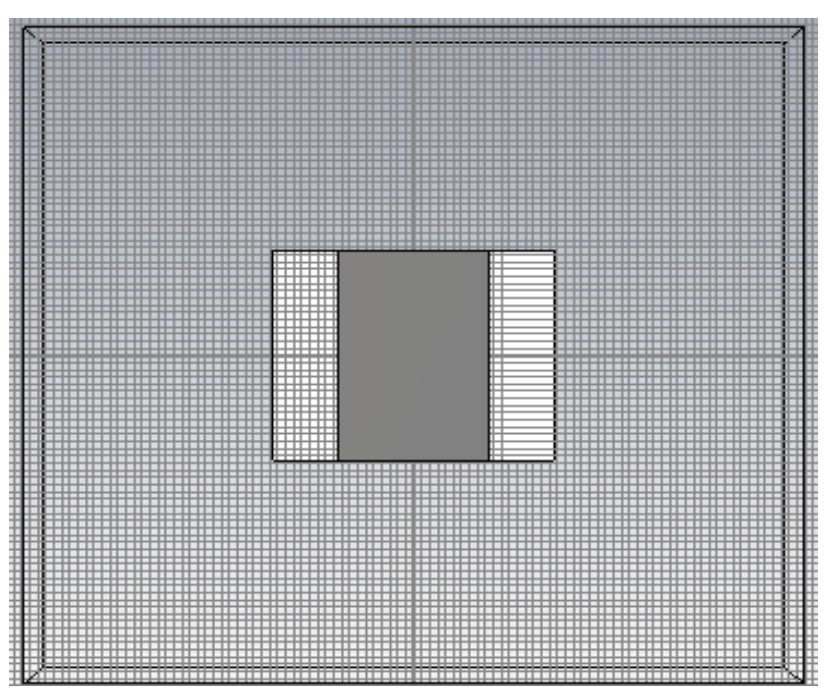

Figure 2: Back view of proposed antenna

\section{SIMULATED RESULTS}

The $S_{11}$ parameters for the proposed antenna have been calculated and the simulated return loss results are shown in Figure 3. The bandwidth at the resonating frequency 3.52 $\mathrm{GHz}$ is $223 \mathrm{MHz}$ with equal to the value of return loss -32.6 $\mathrm{dB}$. The bandwidth of $223 \mathrm{MHz}$ has been achieved as shown in Figure 4. The return loss value $-32.6 \mathrm{~dB}$ shows that there is possible good matching at the frequency point below the -10 $\mathrm{dB}$ region. The return loss variation exhibits impedance match as the function of slot length and width. The feed point locations and dimensions for proposed antenna have been optimized to get the possible impedance match of the antenna. The various parameters were optimized for this proposed antenna design. The bandwidth enhancement technique used slot in patch and reduced ground plane.

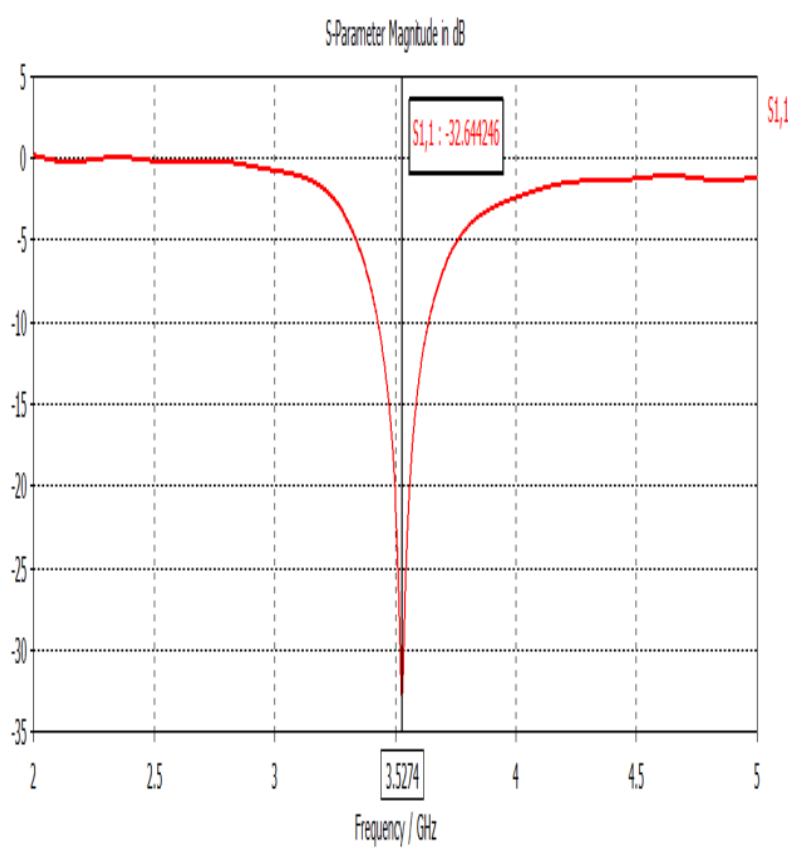

Figure 3: Return Loss of proposed antenna 


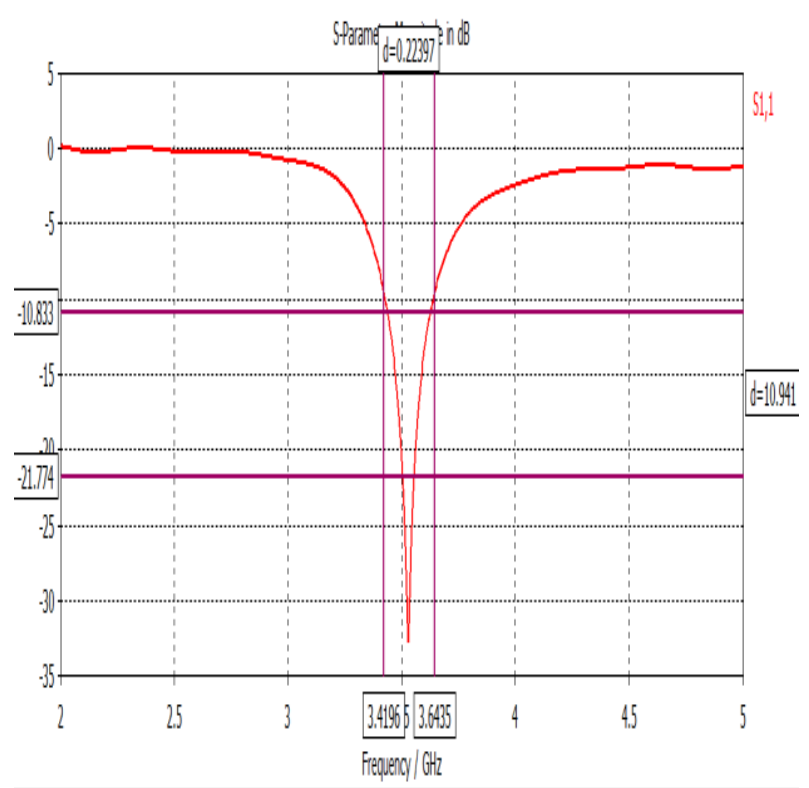

Figure 4: Bandwidth of proposed antenna

The Smith Chart shows the antenna impedance varies with frequency. The designed antenna impedance has been 50.02 ohm as shown in Figure 5. The proposed antenna gain and directivity value has been $3.8 \mathrm{~dB}$ and $4.51 \mathrm{dBi}$ at resonating frequency $3.52 \mathrm{GHz}$ shown in Figure 6 and Figure 7. The VSWR (Voltage Standing Wave Ratio) 1:1.047 has been shown in Figure 8, which value should be lie in between 1 and 2 .

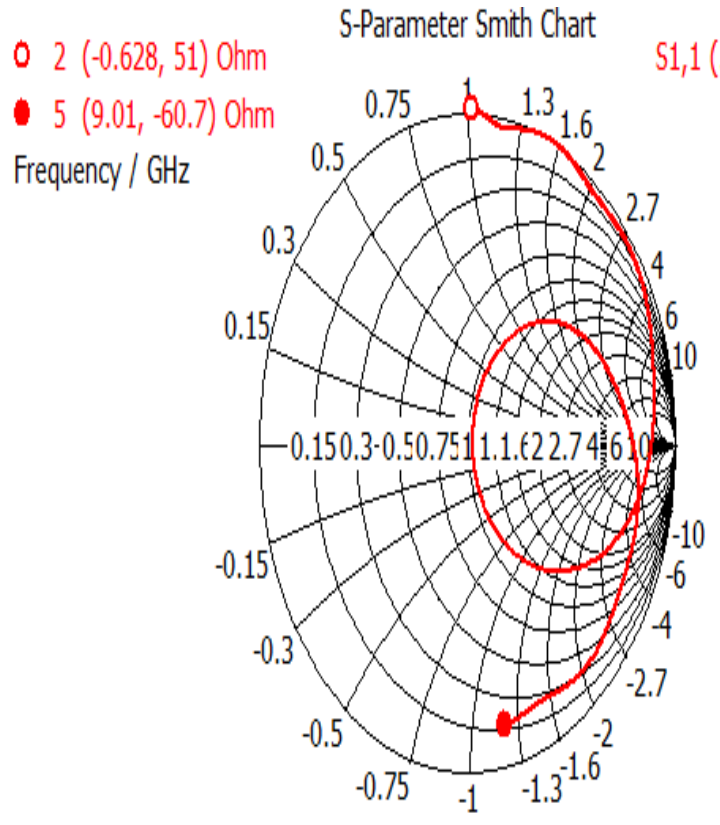

Figure 5: Smith Chart of proposed antenna

The gain of patch antennas can be increased by using multiple patches through connected to an array or by reducing the surface wave which can create ripples in the radiation pattern. Several methods have been proposed to reduce the effects of surface waves [9].

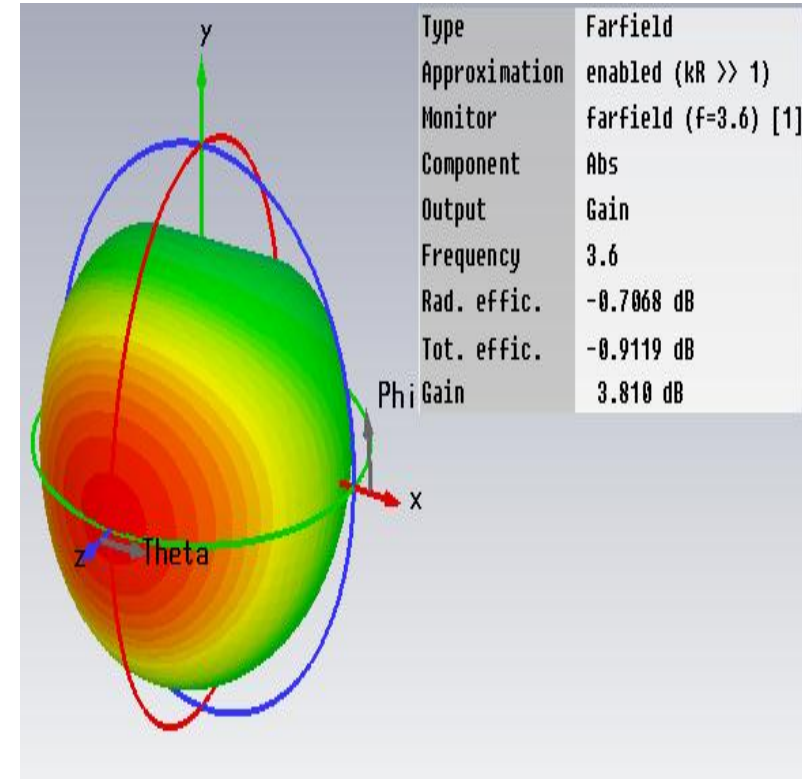

Figure 6: Gain of proposed antenna

Directivity of an antenna defined as "the ratio of the radiation intensity in a given direction from the antenna to the radiation intensity averaged over all directions". The average radiation intensity is equal to the total power radiated by the antenna divided by $4 \pi$. If the directionis not specified, the direction of maximum radiation intensity is implied [1]. There are many methods to reduce the size of the patch shorting wall, shorting pin, slot cutting. The shorting microstrip antenna is a compact antenna but it suffers from of poor gain and degradation in the radiation pattern. An corresponding way to reduce the resonance frequency of the microstrip antenna is to increase the path length of the surface current by cutting slots in the radiating patch [10].

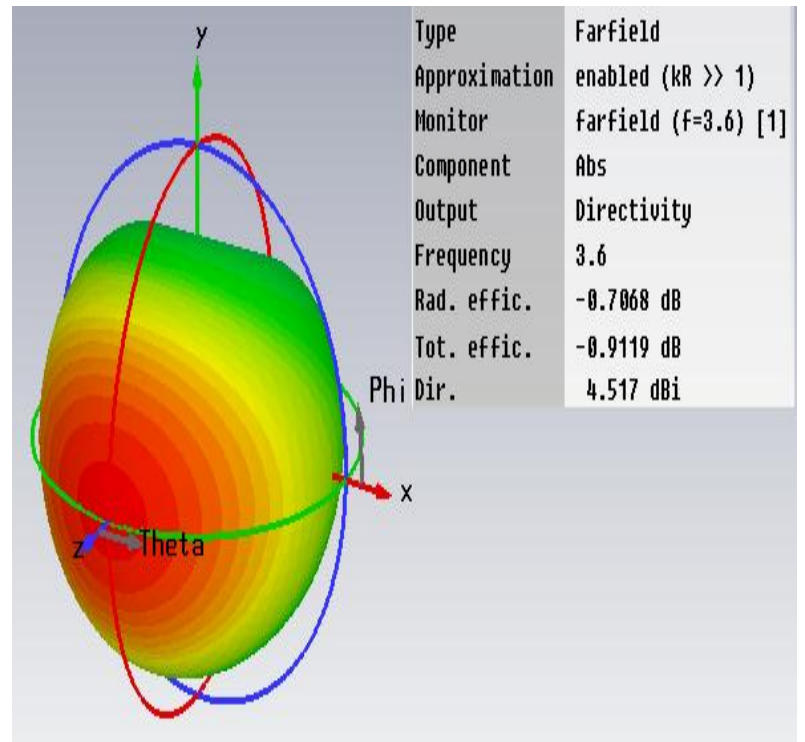

Figure 7: Directivity of proposed antenna

A VSWR of 1:1 means that there is no power being reflected back to the source. 


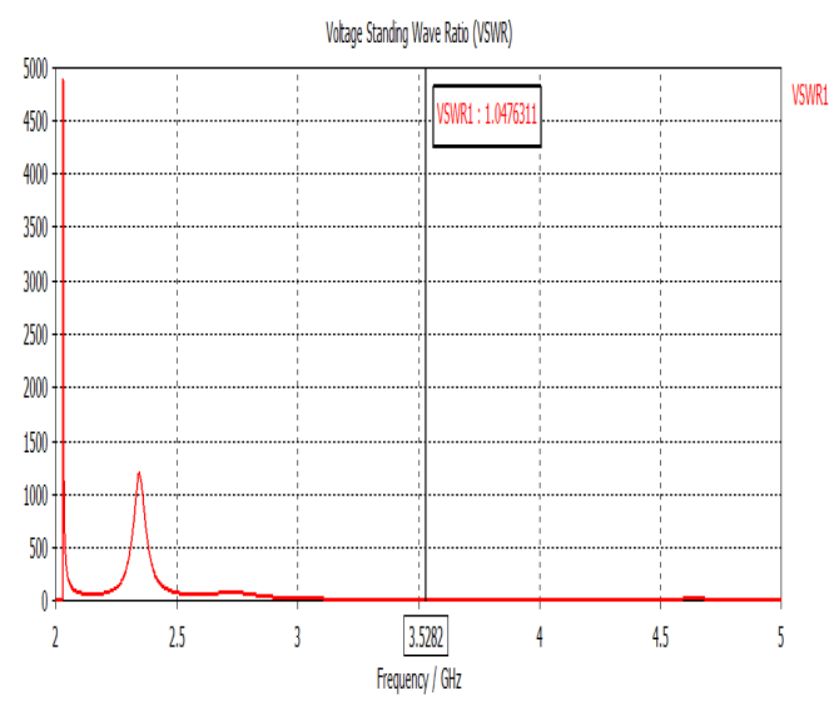

Figure 8: VSWR of proposed antenna

\section{CONCLUSIONS}

The proposed antenna simulated on CST microwave studio. In this paper the slot of patch and reduced ground plane have been analysed. The Rectangular Microstrip Patch Antenna has been analyzed for the varying slot lengths and width in patch and vary ground plane. The designed Microstrip Patch Antenna is operating at frequency $3.52 \mathrm{GHz}$ and covering the range of band is $3.41-3.64 \mathrm{GHz}$ has been simulated on CST Microwave Studio. The Bandwidth of this designed antenna is $223 \mathrm{MHz}$ achieved by reduced ground and slot at $3.6 \mathrm{GHz}$ and impedance matching is 50.02. This return loss value i.e. -32.6 $\mathrm{dB}$ suggests that there is good impedance matching at the frequency point below the $-10 \mathrm{~dB}$ region. The designed antenna is low gain.

\section{ACKNOWLEDGEMENTS}

The Authors are gratefully acknowledge the support of all the staff of Department of Electronics and Science Technology of Lovely Professional University, Phagwara (Punjab).

\section{REFERENCES}

[1] Indrasen Singh, Dr. V.S. Tripathi, "Microstrip Patch Antenna Applications:a Survey”,Motilal Nehru National Institute of Technology Allahabad , 2011 .

[2] Rahul Singh Rathore1, Sudeep Baudha2, Shri kant Pandey3, "A 2.4 GHz Microstrip Patch Antenna with a Single Slot for WLAN Application", Department of Electronics \& Communication, Gyan Gang College of technology,Jabalpur (M.P) , 2012.

[3] Constantine A Balanis Antenna Theory (Analysis and Design) Second Edition, John Wiley \& Sons 2003, and vol 14,812 .

[4] M. T. Islam, "Multi-Slotted Microstrip Patch antenna for wireless Communication”, 2009.

[5] A. Kordzadeh and F. Hojat Kashani, " A New reduced size microstrip patch antenna with fractal defects".

[6] Raj Kumar, J. P. Shinde, M. D. Uplane, " Effect of slots in Ground plane and Patch on Microstrip Antenna performance".

[7] Dinesh Yadav, “ L-Slotted Rectangular Microstrip Patch Antenna" Conference International on Communication systems Network Technologies.

[8] Neha Ahuja, Rajesh Khanna, Jaswinder Kaur,” Design of Single Band Rectangular Patch Antenna for WLAN Application", Department of Electronics\&Comunication Engineering Thapar University, Patiala, Punjab.

[9] Halim Boutayeb, Member, IEEE, and Tayeb A. Denidni. IEEE Member, "Enhancement of a Microstrip Patch Antenna using a Cylindrical Electromagnetic Crystal Substrate".

[10] Bharat Rochani, “ A- Slotted rectangular Microstrip patch antenna, 2012. 